\title{
An Industry Friendly Approach for the Preparation of Magnetic and Electro-Conductive Polyaniline Composite Particles
}

\author{
M. K. Debnath*, H. Ahmad \\ Department of Chemistry, Rajshahi University, Rajshahi 6205, Bangladesh \\ Received 31 May 2017, accepted in final revised form 16 September 2017
}

\begin{abstract}
Recently nano-sized conducting polymers have gained ample attention because of their unique properties and promising potentiality in nanomaterials and nanodevices. Among the conducting polymers, polyaniline (PANi) is the most studied conducting polymers because of its low monomer cost, ease of preparation, high conductivity in doped form, excellent environmental stability, controllable physical and electrochemical properties by oxidation and protonation. In this investigation magnetic PANi composite particles were prepared following a novel approach by using citric acid for the first time as dopant, surfactant and solubilizing agent. As synthesized citric acid doped $\mathrm{Fe}_{3} \mathrm{O}_{4}$ (magnetite)/PANi nanocomposites have been characterized by Fourier Transform Infrared Spectroscopy (FTIR), X-ray diffractometer (XRD), Scanning electron microscope (SEM), Thermogravimetry analysis (TGA). Spectroscopic analyses confirmed the modification of $\mathrm{Fe}_{3} \mathrm{O}_{4}$ nanoparticles by PANi layer. The Magnetic susceptibility results revealed the paramagnetic behavior of $\mathrm{Fe}_{3} \mathrm{O}_{4} / \mathrm{PANi}$ nanocomposite particles. The electrical conductivities of $\mathrm{Fe}_{3} \mathrm{O}_{4} / \mathrm{PANi}$ nanocomposites increased up to certain amount of $\mathrm{Fe}_{3} \mathrm{O}_{4}$ and decreased thereafter.
\end{abstract}

Keywords: Conducting polymer; Citric acid; Oxidative polymerization; Magnetic and Electro-conductive nanocomposite.

(C) 2018 JSR Publications. ISSN: 2070-0237 (Print); 2070-0245 (Online). All rights reserved. doi:4http://dx.doi.org/10.3329/jsr.v9i4.32724 J. Sci. Res. 9 (4), 403-411 (2017)

\section{Introduction}

Polymeric nanocomposites possessing both conducting and ferromagnetic functions are especially useful because they frequently exhibit unexpected hybrid properties synergistically derived from both components [1-3]. The control and design of characteristic structural features on the nanometer scale impart them with tailored properties for diverse applications [4]. Hence interest in the design and controlled fabrication of these composite materials with superior conducting and ferromagnetic properties are continuously increasing [5]. Over the past decades, polyaniline (PANi) has

\footnotetext{
* Corresponding author: mk15debnath@yahoo.com
} 
emerged as one of the most promising organic conducting polymers, owing to its high conductivity and exhibits dramatic changes in its electronic structure and physical property in its protonated state [5]. In addition to these unique properties of PANi, it is highly stable in air. Therefore, several approaches to synthesize nanocomposite consisting of magnetic nanoparticles and conducting PANi have been reported [6-8]. But most of the researchers have synthesized magnetic PANi using either strong inorganic acids viz. phosphoric acid/ $/ \mathrm{HCl} / \mathrm{H}_{2} \mathrm{SO}_{4} /$ dodecyl benzene sulfonic acid sodium salt, DBSA etc. Here DBSA also functioned as a stabilizer in addition to dopant as well [9-11]. All of the strong inorganic acids are environmentally harmful and corrosive to health, skin and expensive. The focal objective of this investigation is to find a less expensive, industry friendly, environmentally benign and economically feasible method for the preparation of electromagnetic PANi nanocomposite particles without using strong inorganic acid. Therefore in this study efforts have been given to synthesize magnetic PANi following a new approach by using citric acid for the first time as surfactant, dopant and solvent. Citric acid is a mild organic acid, less harmful to environment and inexpensive compared to the chemicals reported in the literature. In this study a simple two-step process was applied for the preparation of citric acid doped $\mathrm{Fe}_{3} \mathrm{O}_{4} / \mathrm{PANi}$ nanocomposite particles. In the first step nano-sized $\mathrm{Fe}_{3} \mathrm{O}_{4}$ particles were prepared by co-precipitation of $\mathrm{Fe}^{2+}$ and $\mathrm{Fe}^{3+}$ from their alkaline solutions. Then in the second step $\mathrm{Fe}_{3} \mathrm{O}_{4} / \mathrm{PANi}$ nanocomposite particles were prepared by seeded chemical oxidative polymerization of aniline in presence of variable amount of $\mathrm{Fe}_{3} \mathrm{O}_{4}$ contents using ammonium persulfate (APS) as an oxidant and citric acid as dopant, surfactant and solvent. The schematic illustration for the preparation of $\mathrm{Fe}_{3} \mathrm{O}_{4} / \mathrm{PANi}$ nanocomposite particles is shown in Scheme 1 .
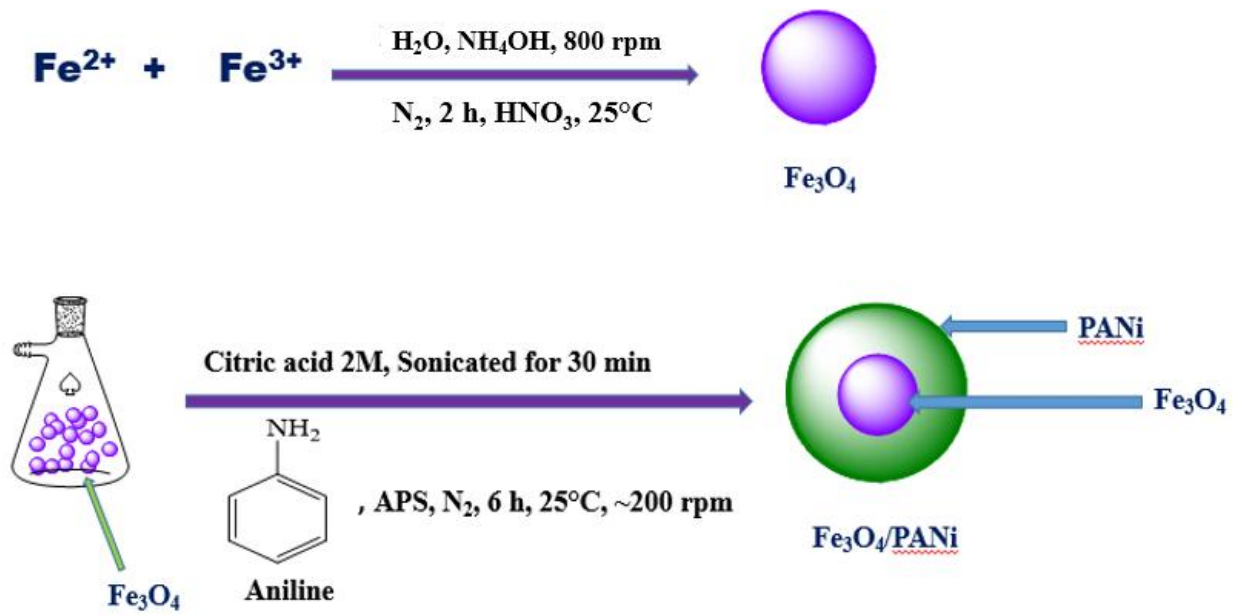

Scheme 1. Reaction scheme for the preparation of $\mathrm{Fe}_{3} \mathrm{O}_{4} / \mathrm{PANi}$ nanocomposite particles. 


\section{Experimental}

\subsection{Monomers and chemicals}

Aniline of monomer grade, purchased from Thomas Baker, (Chemicals) Limited, India, was used without any purification. Ferric chloride $\left(\mathrm{FeCl}_{3}\right)$, ferrous sulphate heptahydrate $\left(\mathrm{FeSO}_{4} \cdot 7 \mathrm{H}_{2} \mathrm{O}\right)$, citric acid, ammonium persulphate (APS) and ammonium hydroxide $\left(\mathrm{NH}_{4} \mathrm{OH}\right)$ and other chemicals were of analar grade. Deionized water was distilled using a glass distillation apparatus.

\subsection{Instruments}

Scanning Electron Microscope, SEM (Hitachi, SU8000, Japan) was used to see the morphology and particle size distribution. IR spectrophotometer, FTIR (Perkin Elmer, FTIR-100, UK), Thermal analyses were carried out using thermal analyzer, TGA (STA 8000, Perkin Elmer, Netherland), XRD (Raigaku, RINT D/max-kA), were used for the analysis of composite structure Sherwood Scientific Magnetic Susceptibility Balance were used for magnetic property analysis. The conductivity of $\mathrm{Fe}_{3} \mathrm{O}_{4} / \mathrm{PANi}$ nanocomposites were measured using the Agilent, PIA-4294A, USA, impedance analyzer at room temperature with operating frequency $100 \mathrm{~Hz}$ to $10 \mathrm{MHz}$.

\subsection{Methodology}

\subsubsection{Synthesis of $\mathrm{Fe}_{3} \mathrm{O}_{4}$ nano-seed particles by co-precipitation method}

Nano-sized $\mathrm{Fe}_{3} \mathrm{O}_{4}$ seed particles were prepared by co-precipitation of $\mathrm{Fe}^{2+}$ and $\mathrm{Fe}^{3+}$ from their aqueous solutions (molar ratio 1:1.87) using 25\% $\mathrm{NH}_{4} \mathrm{OH}$. For this purpose, $\mathrm{FeSO}_{4} .7 \mathrm{H}_{2} \mathrm{O}(2.855 \mathrm{~g})$ and $\mathrm{FeCl}_{3}(3.127 \mathrm{~g})$ were dissolved in water $(90 \mathrm{~g})$. Solutions were then transferred to a $250 \mathrm{~mL}$ three necked round flask followed by addition of $25 \%$ $\mathrm{NH}_{4} \mathrm{OH}(54.05 \mathrm{~g})$ maintained at $25^{\circ} \mathrm{C}$ under a nitrogen atmosphere for $2 \mathrm{~h}$. The reaction mixture was stirred at around $800 \mathrm{rpm}$ with a magnetic stirrer. The prepared $\mathrm{Fe}_{3} \mathrm{O}_{4}$ suspension was treated with $(2 \mathrm{M}) \mathrm{HNO}_{3}(10.0 \mathrm{~g})$ for $15 \mathrm{~min}$ and washed with water until the supernatant was neutral. The black colored particles exhibited a strong magnetic response. The produced $\mathrm{Fe}_{3} \mathrm{O}_{4}$ nanoparticles were dried at $70^{\circ} \mathrm{C}$.

\subsubsection{Preparation of $\mathrm{Fe}_{3} \mathrm{O}_{4} / \mathrm{PANi}$ nanocomposite particles}

Variable amounts $(0.2,0.3$ and $0.6 \mathrm{~g})$ of $\mathrm{Fe}_{3} \mathrm{O}_{4}$ nanoparticles as seed were taken in $100 \mathrm{~g}$ citric acid $(2 \mathrm{M})$ solution and sonicated for $30 \mathrm{~min}$ to make dispersion. $\mathrm{Fe}_{3} \mathrm{O}_{4}$ dispersion was then transferred to a $250 \mathrm{~mL}$ conical flask maintained at $25^{\circ} \mathrm{C}$ under a nitrogen atmosphere. Aniline (1.0 g) was added and the mixture was magnetically stirred at $\sim 200$ rpm for $10 \mathrm{~min}$ to completely dissolve the monomer prior to the addition of APS as oxidant. After the addition of APS, the stirring was continued for $6 \mathrm{hr}$ to complete the 
reaction. The composite particles were washed with $0.2 \mathrm{M} \mathrm{HCl}$ for removing any nonencapsulated $\mathrm{Fe}_{3} \mathrm{O}_{4}$ particles. The product was purified by repeated centrifugation and decantation, replacing the continuous phase by de-ionized distilled water.

\section{Results and Discussion}

\subsection{Structural characterization}

The chemical structure of obtained product was determined by FT-IR spectrum. Fig. 1 represents the IR spectra of PANi particles and $\mathrm{Fe}_{3} \mathrm{O}_{4} / \mathrm{PANi}$ nanocomposite particles prepared with variable $\mathrm{Fe}_{3} \mathrm{O}_{4}$ contents. Since $\mathrm{Fe}_{3} \mathrm{O}_{4}$ belongs to inverse spinel structure, $\mathrm{Fe}^{3+}$ ions are situated in two different lattice sites. The absorption bands at 583 and 435 $\mathrm{cm}^{-1}$ could therefore be attributed to the intrinsic $\mathrm{Fe}-\mathrm{O}$ vibrations of tetrahedral and octahedral $\mathrm{Fe}^{3+}$, respectively $[12,13]$. The peaks at 3,465 and $3,139 \mathrm{~cm}^{-1}$ are ascribed to $\mathrm{N}-\mathrm{H}$ stretching vibrations of amino groups in the structural units of the PANi, while the peaks at 1,560 and $1,500 \mathrm{~cm}^{-1}$ are due to the $\mathrm{C}=\mathrm{C}$ stretching vibration of quinoid rings and benzenoid ring units respectively [13]. The presence of these peaks confirms that the prepared PANi is composed of both amine and the imine units. In the IR spectrum of PANi, the absorption band at $1293 \mathrm{~cm}^{-1}$ shows the $\mathrm{C}-\mathrm{N}$ stretching of secondary aromatic amine [14]. The signal at $1131 \mathrm{~cm}^{-1}$ corresponds to $\mathrm{B}-\mathrm{NH}-\mathrm{B}$, where $\mathrm{B}$ refers to the benzenic type ring [15]. In the IR spectra of $\mathrm{Fe}_{3} \mathrm{O}_{4} / \mathrm{PANi}$ nanocomposite particles the characteristic peaks of PANi and $\mathrm{Fe}_{3} \mathrm{O}_{4}$ are present but show slight shifting toward lower wave number. This may be ascribed to the fact that the interaction of $\mathrm{Fe}_{3} \mathrm{O}_{4}$ and PANi was followed by the formation of $\mathrm{H}$-bonding between the proton on $\mathrm{N}-\mathrm{H}$ and the oxygen atom on the $\mathrm{Fe}_{3} \mathrm{O}_{4}$ surface [16].



Fig. 1. FT-IR spectra of a) PANi particles and $\mathrm{Fe}_{3} \mathrm{O}_{4} / \mathrm{PANi}$ nanocomposite particles prepared with variable $\mathrm{Fe}_{3} \mathrm{O}_{4}$ contents $(\mathrm{g})$; b) 0.2 ; c) 0.3 ; d) 0.6. 


\subsection{Surface morphology}

Fig. 2 represents the SEM images $\mathrm{Fe}_{3} \mathrm{O}_{4} / \mathrm{PANi}$ nanocomposite particles prepared in presence of variable amount of $\mathrm{Fe}_{3} \mathrm{O}_{4}$ nano-seed particles with the aniline content in the recipe remained fixed. It is evident that $\mathrm{Fe}_{3} \mathrm{O}_{4}$ content critically determined the morphology as well as stability of the composite particles. Relative to PANi content the presence of increasing amount of $\mathrm{Fe}_{3} \mathrm{O}_{4}$ nano-seed particles reduces the tendency of aggregation. Irrespective of iron oxide content the composite particles remained mostly spherical or semi-spherical. In the case of highest $\mathrm{Fe}_{3} \mathrm{O}_{4}(0.6 \mathrm{~g})$ content $\mathrm{Fe}_{3} \mathrm{O}_{4} / \mathrm{PANi}$ composite particles were found to align in a chain like fibre structure. The average particle sizes measured from SEM photographs are $\sim 50 \mathrm{~nm}$ for $\mathrm{Fe}_{3} \mathrm{O}_{4}$ nano-seed particles and $\sim 161, \sim 179$, and $\sim 165 \mathrm{~nm}$ for those of $\mathrm{Fe}_{3} \mathrm{O}_{4} / \mathrm{PANi}$ nanocomposite particles prepared with $0.2,0.3$ and $0.6 \mathrm{~g}$ of $\mathrm{Fe}_{3} \mathrm{O}_{4}$ nano-seed particles respectively. The increase in diameter implies that chemical oxidative polymerization occurred mostly at the surface of $\mathrm{Fe}_{3} \mathrm{O}_{4}$ nanoparticles.



Fig. 2. SEM images of a) $\mathrm{Fe}_{3} \mathrm{O}_{4}$ nano-seed particles and $\mathrm{Fe}_{3} \mathrm{O}_{4} / \mathrm{PANi}$ nanocomposites prepared in presence of variable amount of $\mathrm{Fe}_{3} \mathrm{O}_{4}(\mathrm{~g})$; b) 0.2 ; c) 0.3 and d) 0.6.

\subsection{X-ray diffraction}

X-ray diffraction (XRD) studies on the composites reveal the inclusion of $\mathrm{Fe}_{3} \mathrm{O}_{4}$ particles in the composites [17]. Fig. 3 represents the XRD patterns of $\mathrm{Fe}_{3} \mathrm{O}_{4} / \mathrm{PANi}$ nanocomposite particles prepared with variable $\mathrm{Fe}_{3} \mathrm{O}_{4}$ contents. The profile exhibited peaks assignable to reflections due to $\mathrm{Fe}_{3} \mathrm{O}_{4}$ at two theta values of $36.39^{\circ}, 44.36^{\circ}, 57.32^{\circ}$ and $63.75^{\circ}$ are observed only for composite particles prepared by using higher $\mathrm{Fe}_{3} \mathrm{O}_{4}$ contents $(0.3$ and $0.6 \mathrm{~g}$ ). The absence of diffraction signals at lower $\mathrm{Fe}_{3} \mathrm{O}_{4}$ contents is attributed to complete surface coverage with dense PANi shell layer. The characteristic peaks of $\mathrm{Fe}_{3} \mathrm{O}_{4}$ nanoparticles are little broad and less intense, indicating the concealment of the crystalline behavior of $\mathrm{Fe}_{3} \mathrm{O}_{4}$ attributed to its encapsulation by PANi [18]. Moreover, the XRD 
pattern is dominated by a broad signal at two theta value of $21.3^{\circ}$ and $26.78^{\circ}$, which are similar with those usually observe for amorphous PANi $[19,20]$.

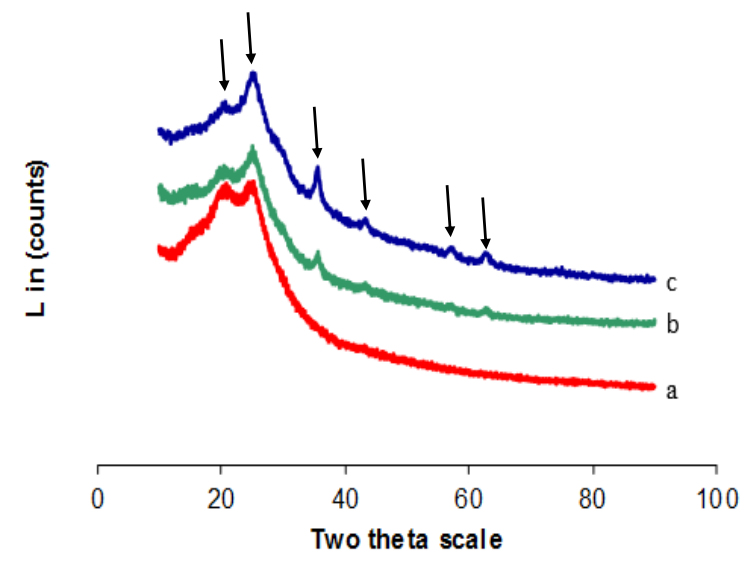

Fig. 3. XRD diffraction patterns of $\mathrm{Fe}_{3} \mathrm{O}_{4} / \mathrm{PANi}$ nanocomposite particles prepared with variable $\mathrm{Fe}_{3} \mathrm{O}_{4}$ contents (g): a) 0.2 ; b) 0.3 ; c) 0.6 .

\subsection{Thermo-gravimetric analysis}

Fig. 4 shows the TGA curves for $\mathrm{Fe}_{3} \mathrm{O}_{4}$ nano-seed particles and $\mathrm{Fe}_{3} \mathrm{O}_{4} / \mathrm{PANi}$ nanocomposite particles prepared with variable iron oxide contents. The mass loss of the reference $\mathrm{Fe}_{3} \mathrm{O}_{4}$ nano-seed particles reached about $7.6 \%$ at $800^{\circ} \mathrm{C}$. This mass loss is associated with the removal of adsorbed water [21]. In the case of $\mathrm{Fe}_{3} \mathrm{O}_{4} / \mathrm{PANi}$ nano composite particles the organic PANi is expected to burn off completely at $800^{\circ} \mathrm{C}$ and the residual part would represent inorganic $\mathrm{Fe}_{3} \mathrm{O}_{4}$ content. It is observed from the Fig. 4. that overall weight loss of composite particles decreased with the increase of $\mathrm{Fe}_{3} \mathrm{O}_{4}$ content and hence more $\mathrm{Fe}_{3} \mathrm{O}_{4}$ is incorporated. The residual mass at $800^{\circ} \mathrm{C}$ for composite particles prepared with $0.2 \mathrm{~g} \mathrm{Fe}_{3} \mathrm{O}_{4}$ is negligibly small $(\sim 1.4 \%)$. But at relatively higher $\mathrm{Fe}_{3} \mathrm{O}_{4}$ content, the residual mass increased to $\sim 7.5$ and $\sim 17 \%$ respectively. This themogravimetric analysis suggests that fairly large amount of $\mathrm{Fe}_{3} \mathrm{O}_{4}$ can be encapsulated in $\mathrm{Fe}_{3} \mathrm{O}_{4} / \mathrm{PANi}$ nanocomposite particles by controlling the magnetite/aniline ratio during seeded chemical oxidative polymerization.

\subsection{Magnetic property of the samples}

Magnetic susceptibility gives idea about magnetic nature. Table 1 shows the values of magnetic susceptibility for $\mathrm{Fe}_{3} \mathrm{O}_{4} / \mathrm{PANi}$ nanocomposite particles. The value of magnetic susceptibility increases with the increase of magnetite content. The positive value indicates that irrespective of $\mathrm{Fe}_{3} \mathrm{O}_{4}$ content the composite particles are strongly paramagnetic. 


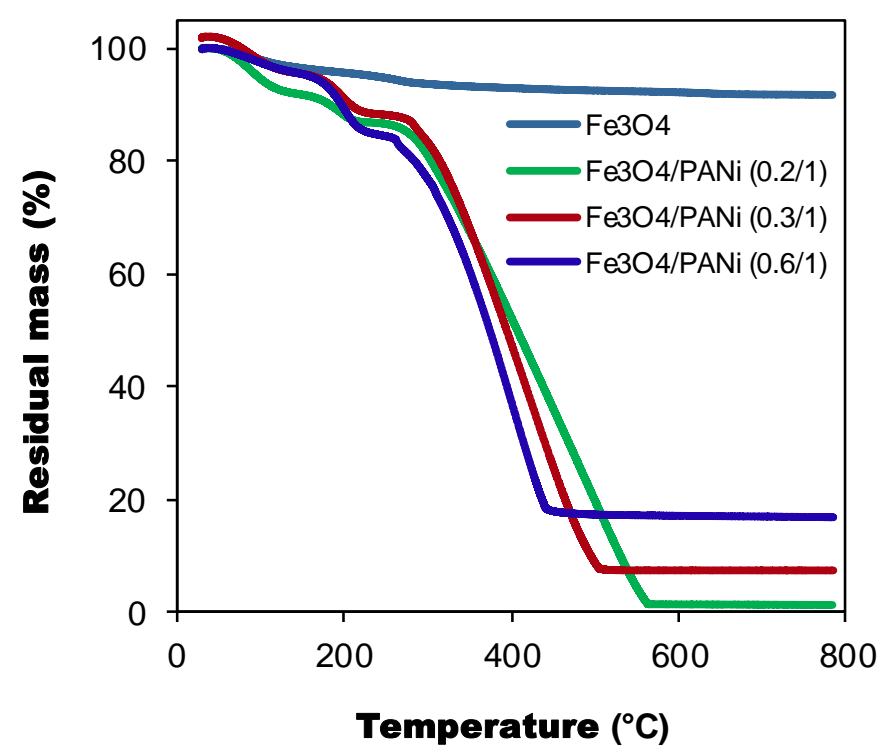

Fig. 4. TGA curves for $\mathrm{Fe}_{3} \mathrm{O}_{4}$ nanoparticles and $\mathrm{Fe}_{3} \mathrm{O}_{4} / \mathrm{PANi}$ nanocomposite composite particles prepared with variable $\mathrm{Fe}_{3} \mathrm{O}_{4}$ contents $(\mathrm{g})$.

Table 1. Magnetic susceptibility of various particles.

\begin{tabular}{llll}
\hline Nanocomposite particles & $\mathrm{Fe}_{3} \mathrm{O}_{4}(\mathrm{~g})$ & PANi $(\mathrm{g})$ & Magnetic susceptibility $\left(\chi_{\mathrm{g}}\right)$ \\
\hline $\mathrm{Fe}_{3} \mathrm{O}_{4} / \mathrm{PANi}$ & 0.2 & 1.0 & $4.02 \times 10^{-5}$ \\
$\mathrm{Fe}_{3} \mathrm{O}_{4} / \mathrm{PANi}$ & 0.3 & 1.0 & $4.79 \times 10^{-5}$ \\
$\mathrm{Fe}_{3} \mathrm{O}_{4} / \mathrm{PANi}$ & 0.6 & 1.0 & $1.17 \times 10^{-4}$ \\
\hline
\end{tabular}

\subsection{Electrical conductivity}

Table 2 shows the effect of $\mathrm{Fe}_{3} \mathrm{O}_{4}$ on the conductivity of $\mathrm{Fe}_{3} \mathrm{O}_{4} / \mathrm{PANi}$ nanocomposite particles. It can be observed that the values of conductivities increase up to $0.3 \mathrm{~g}$ of $\mathrm{Fe}_{3} \mathrm{O}_{4}$ in PANi and decreases thereafter. The initial increase up to $0.3 \mathrm{~g} \mathrm{Fe}_{3} \mathrm{O}_{4}$ is attributed to the extended chain length of PANi, where polarons possess sufficient energy to hop between favourable localized sites. As the amount of $\mathrm{Fe}_{3} \mathrm{O}_{4}$ increases beyond 0.3 , the partial blocking of charge carrier hop occurs and as a result conductivity decreases [22].

Table 2. Electrical conductivity of various particles.

\begin{tabular}{llll}
\hline Nanocomposite particles & Amount of $\mathrm{Fe}_{3} \mathrm{O}_{4}(\mathrm{~g})$ & Amount of PANi $(\mathrm{g})$ & Conductivity $(\mathrm{S} / \mathrm{cm})$ \\
\hline $\mathrm{Fe}_{3} \mathrm{O}_{4} / \mathrm{PANi}$ & 0.2 & 1.0 & $1.06 \times 10^{-3}$ \\
$\mathrm{Fe}_{3} \mathrm{O}_{4} / \mathrm{PANi}$ & 0.3 & 1.0 & $5.3 \times 10^{-3}$ \\
$\mathrm{Fe}_{3} \mathrm{O}_{4} / \mathrm{PANi}$ & 0.6 & 1.0 & $3.2 \times 10^{-3}$ \\
\hline
\end{tabular}




\section{Conclusion}

In this research, it was attempted to prepare and characterize magnetic and electroconductive $\mathrm{Fe}_{3} \mathrm{O}_{4} / \mathrm{PANi}$ nanocomposite particles. The $\mathrm{Fe}_{3} \mathrm{O}_{4} / \mathrm{PANi}$ magnetic and electroconductive nanocomposite nanoparticles with a diameter of $\sim 161-179 \mathrm{~nm}$ were prepared via an in situ polymerization of aniline in an aqueous solution containing the $\mathrm{Fe}_{3} \mathrm{O}_{4}$ magnetic fluid. The synthesized $\mathrm{Fe}_{3} \mathrm{O}_{4} / \mathrm{PANi}$ nanocomposite particles were confirmed from their detailed characterization by FT-IR spectra, TGA thermograms, SEM images, XRD diffraction patterns, magnetic susceptibility results and conductivity data. From the magnetic susceptibility and conductivity data it was found that $\mathrm{Fe}_{3} \mathrm{O}_{4} / \mathrm{PANi}$ nanocomposite particles are magnetic and electro-conductive in nature.

\section{Acknowledgment}

Authors would like to acknowledge Central Science Laboratory, Rajshahi University, Rajshahi; Dr. Klaus Tauer, MPI of Colloid \& Interfaces, Germany; Dr. Hideto Minami, Associate Professor, Graduate School of Science and Technology, Kobe University, Japan; Md. Abdur Rahman Ph.D. student, Yamagata University, Japan, for instrumental support.

\section{References}

1. N. N. Mallikarjuna, S. K. Manohar, P. V. Kulkarni, A. Venkataraman, and T. M. Aminabhavi, J. Appl. Polym. Sci. 97, 1868 (2005). https://doi.org/10.1002/app.21405

2. A. Maity and M. Biswas, J. Appl. Polym. Sci. 94, 803 (2004). https://doi.org/10.1002/app.20944

3. M. Alenxandre and P. Dunois, Mater. Sci. Eng. 28, 1 (2000). https://doi.org/10.1016/S0927-796X(00)00012-7

4. C. C. Holmes, T. Vogt, S. M. Shapiro, S. Wakimoto, and A. P. Ramirez, Science 293, 673 (2001). https://doi.org/10.1126/science.1061655

5. J. Deng, Y. Peng, C. He, X. Long, P. Li, and A. S. C. Chan, Polym. Int. 52, 1182 (2003). https://doi.org/10.1002/pi.1237

6. R. F. Mancilla, J. T. E. Galindo, E. V. Santiago, C. A. H. Escobar, A. V. Rios, and E. A. Z. Contreras, Int. J Theore. Appl. Nanotechnol. 4, 1 (2016).

7. D. L. Zhao, H. L. Zhang, X. W. Zeng, Q. S. Xia, and J. T. Tang. Biomed. Mater. 1, 198 (2006). https://doi.org/10.1088/1748-6041/1/4/002

8. H. Gu, Y. Huang, Xi Zhang, Q. Wang, J. Zhu, L. Shao, N. Haldolaarachchige, D. P. Young, S. Wei, and Z. Guo, Polymer 53, 801 ( 2012). https://doi.org/10.1016/j.polymer.2011.12.033

9. M. Petrychuk, V. Konvalenko, A. Pud, N. Ogurtsov, and A. Gubin, Phys. status. Solid. 207, 442 (2010). https://doi.org/10.1002/pssa.200824421

10. F. G. d. Souza Jr, J. A. Marins, J. C. Pinto. G. E. d. Oliveira, C. M. Rodrigues, and L. M. T. R. Lima, J. Mater. Sci. 45, 5012 (2010).

11. S. H. Hosseini, R. Rahimi, and H. Kerdari, Polym. J. 43, 745 (2011). https://doi.org/10.1038/pj.2011.47

12. K. Basavaiah, Y. P. Kumar, and A. V. P. Rao, Appl. Nanosci. 12, 148 (2012).

13. D. R. Devi, Y. P. Kumar, and K. Basavaiah, Int. J. Sci. Res. 5(10), 2319 (2016).

14. S. Xuan, Y. X. J. Wang, K. C. F. Leung, and K Shu, J. Phys. Chem. 112, 18804 (2008).

15. Y. Li, C. Zhu and J. Kan, Metals 5, 2403 (2015). https://doi.org/10.3390/met5020547 
16. M. A. Adamu, M. K. Mustafa, and N. N. B. Ruslan, ARPN J. Eng. Appl. Sci. 11, 16 (2016).

17. S. Radhakrishnan, S. Prakash, Chepuri R. K. Rao, and M. Vijayan. Electrochem. Solid-State Lett. 12, 84 (2009). https://doi.org/10.1149/1.3074315

18. S. Kumar and S. Jain, J. Chem. Article ID 837682 (2014).

19. L. Zhang, M. Wan, and Y. Wei. Macromol. Rapid Commun. 27, 366 (2006). https://doi.org/10.1002/marc.200690045

20. Z. Taghipoura, H. Eisazadeh, and M. Tanzifi, Int. J. Eng. 27, 227 (2014).

21. N. Arsalani, H. Fattahi, and M. Nazarpoor, eXPRESS Polym. Lett. 4, 329 (2010). https://doi.org/10.3144/expresspolymlett.2010.42

22. S. Khasim, S. C. Raghavendra, M. Revanasiddappa, K. C. Sajjan, M. Lakshmi, and M. Faisal, Bull. Mater. Sci. 34, 1557 (2011). https://doi.org/10.1007/s12034-011-0358-Z 